\title{
Bone Marrow Necrosis and Elevated Plasma Levels of Fas Ligand in a Patient with Aggressive Natural Killer Cell Leukemia
}

\author{
Yoshiko (Fujimoto) Hirakawa ${ }^{1^{*}}$, Kyoko (Taniguchi) Yoshihara ${ }^{2}$, Hiroto Kaneko ${ }^{3}$, Hitoji Uchiyama ${ }^{1}$, Junya Kuroda ${ }^{4}$ and Masafumi Taniwaki ${ }^{4}$ \\ ${ }^{1}$ Department of Hematology, Japanese Red Cross Kyoto Daiichi Hospital, Honmachi, Higashiyama-ku, Kyoto, Japan \\ ${ }^{2}$ Division of Hematology, Department of Internal Medicine, Hyogo College of Medicine, Mukogawa-cho, Nishinomiya City, Hyogo, Japan \\ ${ }^{3}$ Department of Hematology, Aiseikai Yamashina Hospital, Takehana-Shichono-cho, Yamashina-ku, Kyoto, Japan \\ ${ }^{4}$ Department of Hematology and Oncology, Kyoto Prefectural University of Medicine Graduate School of Medical Science, Kyoto, Japan
}

"Corresponding author: Yoshiko (Fujimoto) Hirakawa, Department of Hematology, Japanese Red Cross Kyoto Daiichi Hospital, 15-749 Honmachi, Higashiyama-ku, Kyoto 605-0981, Japan, Tel: +81-75-561-1121; Fax: +81-75-561-6308; E-mail: ysk-fjmt@koto.kpu-m.ac.jp

Rec date: June 28, 2016, Acc date: July 25, 2016, Pub date: July 31, 2016

Copyright: @ 2016 Hirakawa Y, et al. This is an open-access article distributed under the terms of the Creative Commons Attribution License, which permits unrestricted use, distribution, and reproduction in any medium, provided the original author and source are credited.

\begin{abstract}
Fas is type I membrane protein, expressed on various tissue including hematopoietic cell. Its ligand (FasL), a member of the tumor necrosis factor (TNF) family, which includes two forms of a membrane-bound form and a soluble one, induces apoptosis of Fas-bearing cells through cytotoxic activity. FasL is undetectable in the serum of healthy person, whereas it is high in that from patients with T-large granular lymphocytic leukemia and natural killer (NK) cell lymphoma. We experienced a case of aggressive NK cell leukemia presenting severe bone marrow necrosis (BMN) after administrating granulocyte colony stimulating factor (G-CSF). In concern with a relation to cytokine, his serum FasL was examined and found to be extremely elevated. Administration of G-CSF under a large quantity of soluble FasL might play an important role in the pathogenesis of BMN through apoptosis of hematopoietic cells in the bone marrow.
\end{abstract}

Keywords: Aggressive natural killer cell leukemia (ANKL); Fas ligand; Bone marrow necrosis

\section{Introduction}

Aggressive natural killer cell leukemia (ANKL) has aggressive features such as systemic tissue injury including bone marrow, resulting in pancytopenia. Although leukemic cells are thought to cause these damages, the mechanism is unclear.

Fas, type I membrane protein, is expressed on various tissue including hematopoietic cells and its ligand FasL, a member of the tumor necrosis factor (TNF) family, is limitedly expressed on activated T-cells or activated NK-cells. Although membrane-bound FasL can be converted to a soluble form (sFasL) [1], sFasL is undetectable in the serum of healthy person and that of patients with most subtypes of lymphoma or leukemia. It is contrarily elevated in patients with T-large granular lymphocytic (LGL) leukemia and natural killer (NK) cell lymphoma [2-6], suggesting that Fas-FasL system plays a crucial role in characteristic systemic tissue damage observed in these types of hematological tumor [7-9]. We report a case of ANKL accompanied by bone marrow necrosis $(\mathrm{BMN})$ with severe bone pain after granulocyte colony-stimulating factor (G-CSF) administration. Serum level of sFasL was increased and G-CSF might trigger FasL-induced apoptosis of bone marrow.

\section{Case Report}

A 25-year-old man presented to local doctor because of high fever $\left(39.3^{\circ} \mathrm{C}\right.$ ) and thrombocytopenia (platelet count $\left.57 \times 10 \mathrm{E} 9 / \mathrm{l}\right)$ in September 2007. He was diagnosed as Epstein-Barr virus (EBV) associated hemophagocytic lymphohistiocytosis (HLH). Even though he was treated with methylprednisolone pulse therapy, his symptom did not improve, so he was introduced to our hospital in October 2007. Physical examination exhibited severe hepatosplenomegaly. Laboratory findings on admission revealed moderate anemia, thrombocytopenia (hemoglobin $11.3 \mathrm{~g} / \mathrm{dl}$, platelet count $12 \times 10 \mathrm{E} 9 / \mathrm{l})$ and elevation of lactate dehydrogenase (LDH) (995 IU/l), ferritin (9915 $\mathrm{ng} / \mathrm{ml})$, and soluble interleukin-2 receptor (sIL-2R) $(6450 \mathrm{U} / \mathrm{ml})$ (Table 1). Serological analyses of EBV show the pattern of infection in the

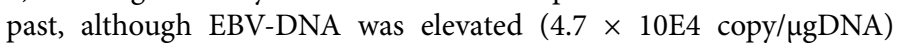
(Table 1).

\begin{tabular}{|c|c|c|c|c|c|c|c|c|}
\hline WBC & $4.8 \times 10$ & 9/L & LDH & 995 & IU/1 & PritINR & 0.98 & \\
\hline Neut & 93 & $\%$ & AST & 50 & IU/1 & APTT & 36.4 & $\mathrm{sec}$ \\
\hline Lym & 3 & $\%$ & ALT & 81 & IU/1 & FIG & 202 & $\mathrm{mg} / \mathrm{d} 1$ \\
\hline Eos & 0 & $\%$ & ALP & 235 & $\mathrm{IU} / 1$ & FDP & 16.3 & $\mathrm{pg} / \mathrm{m} 1$ \\
\hline Baso & 0 & $\%$ & $y$-GTP & 82 & $\mathrm{IU} / 1$ & sIL-2R & 6540 & $\mathrm{U} / \mathrm{ml}$ \\
\hline
\end{tabular}


Citation: $\quad$ Yoshiko (Fujimoto) Hirakawa, Kyoko (Taniguchi) Yoshihara, Hiroto Kaneko, Hitoji Uchiyama, Junya Kurodam, et al. (2016) Bone Marrow Necrosis and Elevated Plasma Levels of Fas Ligand in a Patient with Aggressive Natural Killer Cell Leukemia. Gen Med (Los Angeles) 4: 263. doi:10.4172/2327-5146.1000263

Page 2 of 4

\begin{tabular}{|l|l|l|l|l|l|l|l|l|}
\hline Mono & 2 & $\%$ & TP & 5.8 & g/dl & VCA-IgG & 80 folds \\
\hline & & & & & g/dl & VCA-IgM & $<10$ \\
\hline $\mathrm{Hb}$ & 11.3 & $\mathrm{~g} / \mathrm{dl}$ & Alb & 3.1 & $\mathrm{mg} / \mathrm{di}$ & EADR-IgG & \\
\hline $\mathrm{Ht}$ & 32.4 & $\%$ & T-Bil & 1.36 & $\mathrm{mg} / \mathrm{di}$ & EADR-IgA & $<10$ \\
\hline $\mathrm{PLT}$ & $12 \times 10$ & $9 / \mathrm{L}$ & CRP & 1.77 & & EBNA & $<10$ \\
\hline
\end{tabular}

Table 1: Laboratory data on admission.

Bone marrow aspiration showed marked hemophagocytosis (3.2\%) but no atypical cells were detected. Flow cytometry of bone marrow disclosed 5.4\% of CD3-negative and CD56-positive cells (Figure 1).

a
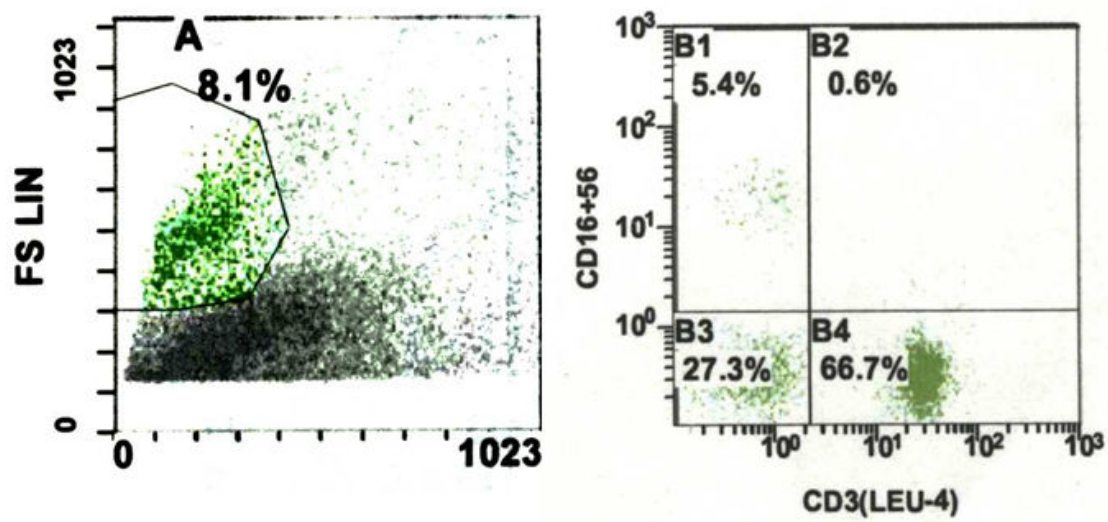

$\mathrm{b}$
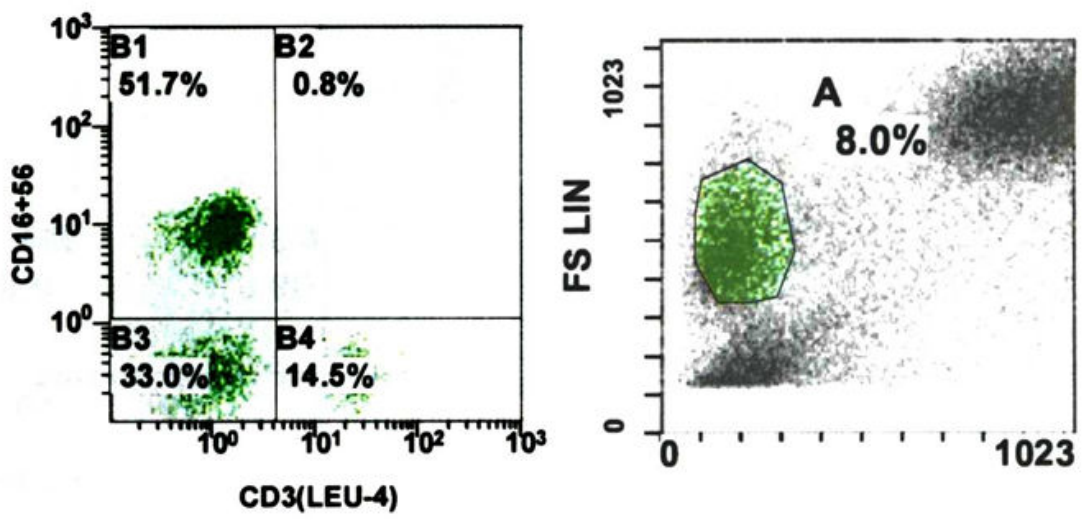

Figure 1: Flow cytometry of Bone marrow aspiration (a) CD3-CD56+cell is positive for $5.4 \%$ of marrow cells at first visit to our hospital.(b) CD3-CD56+cell is positive for $51.7 \%$ of marrow cells at the time when BMN occured.

Monoclonality of EBV terminal repeat sequence was confirmed in mononuclear cells obtained from peripheral blood.Combined immunochemotherapy consisting of cyclosporine A, dexamethasone, and etoposide was begun on 2 hospital day. His fever fell to a low grade level, but pancytopenia was progressive. Concerning of myelosuppression by etoposide, $75 \mu \mathrm{g}$ of G-CSF was daily administered. On the third day of G-CSF, sudden onset of bone pain and fever occurred. Laboratory investigation showed pancytopenia (WBC $0.3 \times 10 \mathrm{E} 9 / 1$, platelet count $9 \times 10 \mathrm{E} 9 / \mathrm{l})$ and elevation of $\mathrm{LDH}$ level (1515 IU/l). Peripheral blood smear showed leukoerythroblastosis. Bone marrow aspiration smear exhibited increase of small to medium-sized naked lymphoid cellsand nucleated cells containing basophilic cytoplasm. Most of granulocytic cells were destroyed (Figure 2). 
Citation: $\quad$ Yoshiko (Fujimoto) Hirakawa, Kyoko (Taniguchi) Yoshihara, Hiroto Kaneko, Hitoji Uchiyama, Junya Kurodam, et al. (2016) Bone Marrow Necrosis and Elevated Plasma Levels of Fas Ligand in a Patient with Aggressive Natural Killer Cell Leukemia. Gen Med (Los Angeles) 4: 263. doi:10.4172/2327-5146.1000263

a

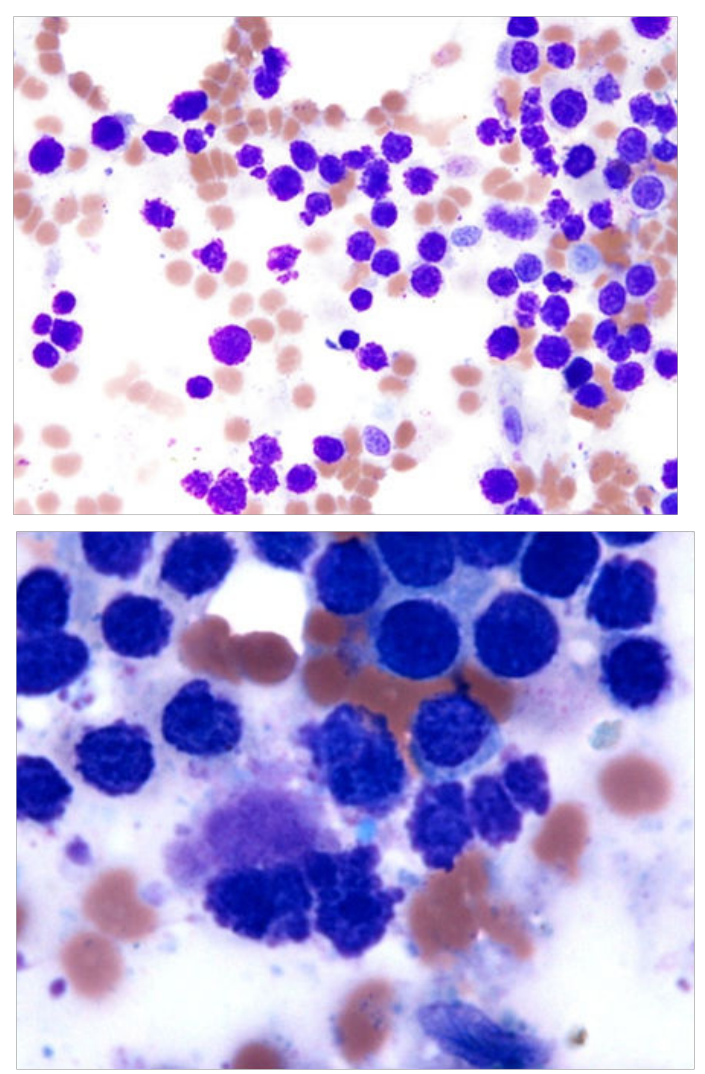

b

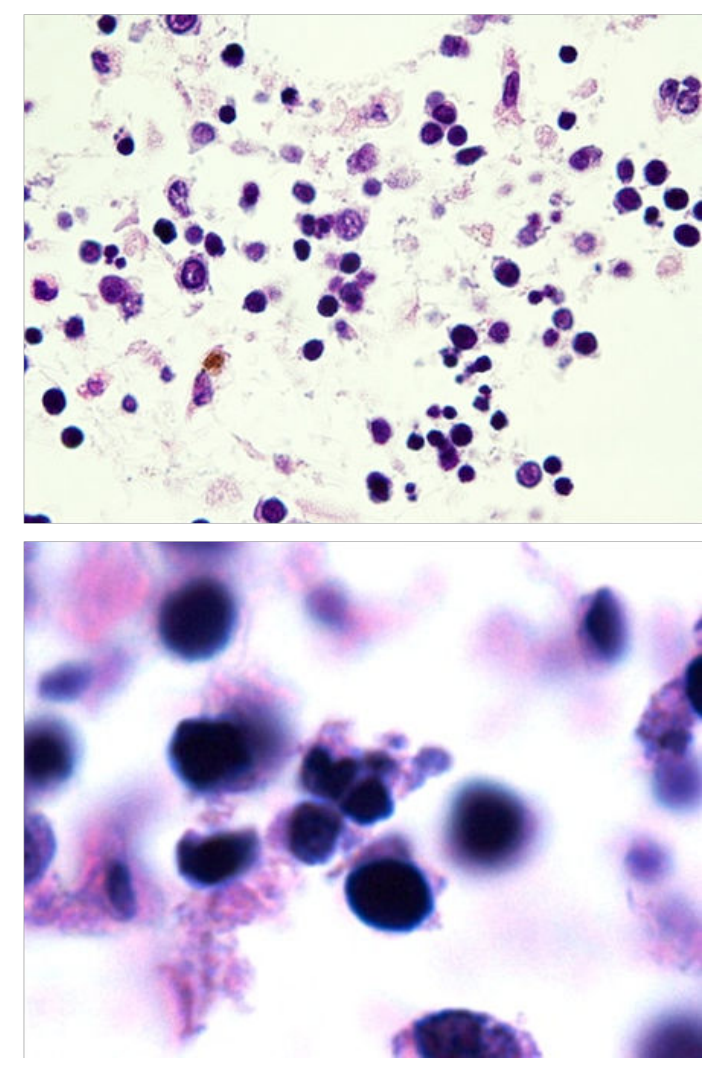

Figure 2: Bone marrow aspirates at the time when BMN occurred a) May-Giemsa stain $\times 100$. b) Haematoxylin and eosin $\times 40$ ). Most of nucleated cells contain picnotic nucleus. Outline of their cytoplasm is often illegible. Elevation of small to medium-sized naked lymphoid cellsand nucleated cells containing basophilic cytoplasm. Most of granulocytic cells were destroyed and hemophagocytosis. These indicate massive necrosis of hematopoietic cells.

Flow cytometry of bone marrow showed $51.7 \%$ of CD3-negative and CD56-positive cells (Figure 1), whereas that were only $5.6 \%$ at the initial presentation (Figure 1). Furthermore, Magnetic Antigen Cell Sorting System (MACS) revealed a higher proportion of EBV infection among CD56 positive-cells than other types of lymphocytes (Figure 3). Based on these findings, the patient was diagnosed as ANKL. After GCSF was discontinued, the patient was free from pain within 3 days, however, the elevation of LDH continued for about a month. Salvage regimen consisting of ifosfamide, dexamethasone, and L-asparaginase brought only a transient improvement in clinical symptoms. No further conventional chemotherapy was undertaken since treatment toxicities without benefit were anticipated. Finally, the patient received allogeneic peripheral blood stem cell transplantation (PBSCT) from HLA-one locus mismatched EBV-seropositive father. The conditioning regimen consisted of total body irradiation (TBI) of 10Gy and highdose intravenous cyclophosphamide $(60 \mathrm{mg} / \mathrm{kg}$ once daily for 2 days), followed by the infusion of PBSC containing $3.7 \times 10 \mathrm{E} 6 \mathrm{CD} 34$ positive cells $/ \mathrm{kg}$.

\begin{tabular}{|c|c|}
\hline Mononuclear cell & EBV copy number \\
\hline CD3+ lymphocyte & 41,736 copy/ugDNA \\
\hline CD8+ lymphocyte & 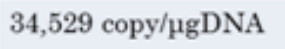 \\
\hline CD19+ lymphocyte & 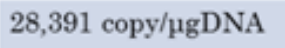 \\
\hline CD56+ lymphocyte & 262,069 copy/ugDNA \\
\hline
\end{tabular}

Figure 3: EB viral copy number in peripheral blood mononuclear cells. Magnetic Antigen Cell Scoring System (MACS) showed EBV infected CD56 positive cells dominantly.

Standard-dose FK506 and short-term methotrexate were used for prophylaxis of graft-versus-host disease. Although engraftment was 
Citation: $\quad$ Yoshiko (Fujimoto) Hirakawa, Kyoko (Taniguchi) Yoshihara, Hiroto Kaneko, Hitoji Uchiyama, Junya Kurodam, et al. (2016) Bone Marrow Necrosis and Elevated Plasma Levels of Fas Ligand in a Patient with Aggressive Natural Killer Cell Leukemia. Gen Med (Los Angeles) 4: 263. doi:10.4172/2327-5146.1000263

Page 4 of 4

completed at day 10, ANKL was relapsed presenting fever up, elevation of $\mathrm{LDH}$, and exacerbation of hepatosplenomegaly within a few weeks. The disease was progressive despite administration of dexamethasone and etoposide. Although the second transplantation was intended, he died of fungal infection.

Since we hypothesized that the interaction between Fas and FasL caused of BMN, we examined his serum sFasL concentration sequentially at the timings of BMN and after chemotherapy. His serum was sent to the Department of HSCT Data Management, Nagoya University School of Medicine. Enzyme immunoassay was employed and sFasL was found to be elevated to $1050 \mathrm{pg} / \mathrm{ml}$ on the day of BMN diagnosis (lower than $0.1 \mathrm{ng} / \mathrm{ml}$ in normal serum). Maximum titer was $1350 \mathrm{pg} / \mathrm{ml} 10$ days after (Figure 4).

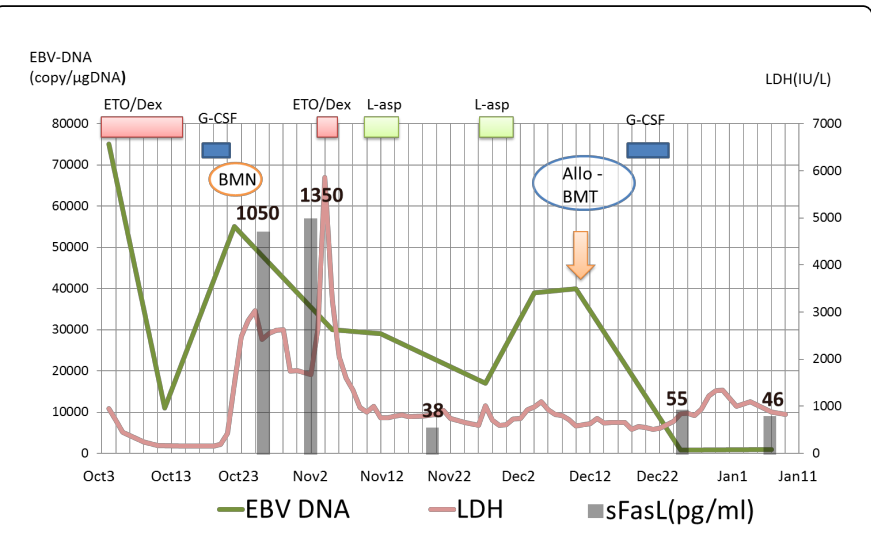

Figure 4: Clinical course and serum level of sFas, LDH, and EBV DNA before and after chemotherapy. At the onset of BMN, the levels of LDH, sFasL and EBV-DNA were elevated, and decreased after chemotherapy.

ETO; Etoposide, Dex; Dexamethasone, L-asp; L-asparaginase, sFasL; soluble Fas ligand, LDH; lactate dehydrogenase, BMN; Bone marrow necrosis, BMT; Bone marrow transplantation.

\section{Discussion}

Standard therapy for ANKL has not yet been established. Pglycoprotein expressed by NK cells is reported to be responsible for its refractoriness to chemotherapy [8]. On the other hand, Kawa et al. [9] introduced immunosuppressive and cytoreductive therapy with prednisolone, cyclosporine A and etoposide to a case of systemic active EBV infection. However, it did not benefit our case and pancytopenia was progressive even though symptoms fell down. Several researchers reported high serum levels of sFasL in patients with NK- or T-cell LGL leukemia as well as NK cell lymphoma [2-6]. However, despite over production of FasL in NK cell leukemia, tissue damage such as BMN does not always occur. It is presumed that the sensitivity of the target cells to the sFasL is different among the patients [7]. In this case, serum level of sFasL was increased and subsequently to G-CSF administration, BMN happened [10-13]. Takenaka et al. [12] reported that hematopoietic cells cultured in the presence of G-CSF showed induction of Fas expression. These results suggest that G-CSF triggered FasL-induced apoptosis of bone marrow under the high concentration of sFasL. However, controversial reported that G-CSF inhibits Fastriggered apoptosis in bone marrow cells [14]. The participation of GCSF to BMN is thus unclear. Further accumulation of similar cases is required.

\section{Acknowledgement}

We thank Dr Hiroshi Kimura (Department of Virology, Nagoya University Graduate School of Medicine, Nagoya, Japan) for measurement of EBV DNA by the real-time polymerase chain reaction method, and Dr Ritsuro Suzuki(Department of HSCT Data Management, Nagoya University School of Medicine, Nagoya, Japan) for measurement of sFasL.

\section{References:}

1. Sato K, Kimura F, Nakamura Y, Murakami H, Yoshida M, et al. (1996) An aggressive nasal lymphoma accompanied by high levels of soluble Fas ligand. Br J Haematol 94: 379-382.

2. Tanaka M, Suda T, Haze K, Nakamura N, Sato K, et al. (1996) Fas ligand in human serum. Nat Med 2: 317-322.

3. Kato K, Ohshima K, Ishihara S, Anzai K, Suzumiya J, et al. (1998) Elevated serum soluble Fas ligand in natural killer cell proliferative disorders. Br J Haematol 103: 1164-1166.

4. Murayama T, Koizumi T, Das H, Kobayashi Y, Kajimoto K, et al. (1999) Soluble Fas ligand in natural killer cell lymphoma. Am J Hematol 62: 253-255.

5. Kaizu K, Maeda M, Ohkawa T, Hayashida M, Nakajima S, et al. (2004) Marked elevation of soluble Fas ligand and cytokine secretion after splenectomy in aggressive natural killer cell leukemia/lymphoma. Leuk Lymphoma 45: 2291-2294.

6. Makishima H, Ito T, Momose K, Nakazawa H, Shimodaira S, et al. (2007) Chemokine system and tissue infiltration in aggressive NK-cell leukemia. Leuk Res 31: 1237-1245.

7. Tani R, Ozaki S, Kosaka M, Fujiwara S, Shibata H, et al. (1999) Fas ligandinduced apoptosis of hepatocytes in natural killer cell leukaemia. Br J Haematol 106: 709-712.

8. Mori N, Yamashita Y, Tsuzuki T, Nakayama A, Nakazawa M, et al. (2000) Lymphomatous features of aggressive NK cell leukaemia/lymphoma with massive necrosis, haemophagocytosis and EB virus infection. Histopathology 37: 363-371.

9. Moritake H, Obara M, Sameshima N, Asada Y, Komatsu H, et al. (2015) Analysis of the molecular mechanism underlying bone marrow necrosis with acute lymphoblastic leukemia. Int J Hematol 102: 349-356.

10. Yamamoto T, Iwasaki T, Watanabe N (1993) Expression of multidrug resistance P-glycoprotein on peripheral blood mononuclear cells of patients with granular lymphocyte-proliferative disorders. Blood 81: 1342-1346.

11. Kawa K, Okamura T, Yasui M, Sato E, Inoue M (2002) Allogeneic hematopoietic stem cell transplantation for Epstein-Barr virus-associated T/NK-cell lymphoproliferative disease. Crit Rev Oncol Hematol 44: 251-257.

12. Takenaka K, Nagafuji K, Harada M, Mizuno S, Miyamoto T, et al. (1996) In vitro expansion of hematopoietic progenitor cells induces functional expression of Fas antigen (CD95). Blood 88: 2871-2877.

13. Niho Y, Asano Y (1998) Fas/Fas ligand and hematopoietic progenitor cells. Curr Opin Hematol 5: 163-165.

14. Schmidt-Mende J, Tehranchi R, Forsblom AM, Joseph B, Christensson B, et al. (2001) Granulocyte colony-stimulating factor inhibits Fas-triggered apoptosis in bone marrow cells isolated from patients with refractory anemia with ringed sideroblasts. Leukemia 15: 742-751. 